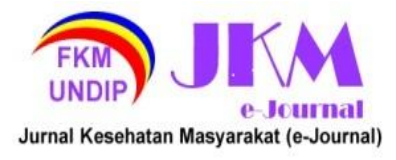

\author{
JURNAL KESEHATAN MASYARAKAT (e-Journal) \\ Volume 10, Nomor 1, Januari 2022 \\ ISSN: 2715-5617 / e-ISSN: 2356-3346 \\ http://ejournal3.undip.ac.id/index.php/jkm
}

\title{
PENERAPAN MANAJEMEN RISIKO KESELAMATAN DAN KESEHATAN KERJA DI RUMAH SAKIT ISLAM SURABAYA A. YANI
}

\author{
Muhammad Huda Firmansyah ${ }^{1 *}$ \\ ${ }^{1}$ Program Studi S1 Kesehatan Masyarakat, Fakultas Kesehatan, Universitas Nahdlatul Ulama Surabaya, Jl. Raya \\ Jemursari No. 57, Wonocolo, Surabaya \\ *Corresponding author: muhammadhuda049.km17@student.unusa.ac.id
}

\begin{abstract}
Risk management is a preventive effort for a company, especially those engaged in the service sector, which is very prone to errors and complaints. For this reason, it is necessary to map the risks that occur in accordance with the work unit in it which is expected to minimize the number of accidents or errors in both patients, visitors and employees in the hospital. In the 2019 patient safety incident report data at the Surabaya A. Yani Islamic Hospital, it was found that there were incidents which included near miss 93\%, not injured 4\%, unexpected events $3 \%$ and Sentinel $0 \%$. The purpose of this study was to identify and identify the application of occupational safety and health risk management at the A. Yani Islamic Hospital in Surabaya. This thesis is a qualitative research with a case study method with the aim of fully describing the implementation of K3 risk management at Surabaya A. Yani Hospital based on observation, survey and documentation data on 37 units and hospital workplaces by identifying risks. , analyze and find risk control measures. The results showed that the implementation of K3 risk management in the Islamic Hospital of Surabaya A. Yani based on the results of risk identification obtained as many as 25 risks in the graha building and the old building which were further analyzed by finding 15 moderate risks and 10 high risks. can be done is by repairing damaged infrastructure and improving the existing security system at the A. Yani Islamic Hospital in Surabaya. The conclusion in this study is the implementation of K3 risk management at the Islamic Hospital of Surabaya A. Yani based on the process of risk identification and risk analysis, there are 25 potential risks, of which there are 15 moderate risks and 10 high risks that can potentially cause accidents to employees, visitors and patients. In this case, control efforts are made to minimize the number of incidents and accidents.
\end{abstract}

Keywords: Risk Management, Hospital, Occupational Health and Safety.

\section{PENDAHULUAN}

Keselamatan dan Kesehatan Kerja (K3) adalah suatu usaha pencegahan yang dibuat untuk pekerja atau buruh maupun pengusaha sebagai pencegahan timbulnya kecelakaan kerja dan penyakit akibat hubungan pekerjaan di dalam lingkungan kerja dengan cara mengenali potensi yang akan menimbulkan kecelakaan kerja dan penyakit akibat kerja (PAK). Undang- Undang RI No. I Tahun 1970 tentang keselamatan kerja meyatakan bahwa tempat kerja adalah tempat dilakukan pekerjaan untuk keperluan suatu usaha di mana terdapat tenaga kerja yang bekerja dan kemungkinan adanya bahaya di tempat kerja tersebut. Tempat kerja ini mencakup semua tempat kegiatan usaha yang bermotif ekonomi maupun sosial.

Peraturan Menteri Tenaga Kerja Nomor PER.05/MEN/1996 menyebutkan bahwa Sistem Manajemen Keselamatan dan Kesehatan Kerja yang selanjutnya disebut Sistem Manajemen K3 adalah bagian dari sistem manajemen secara keseluruhan yang meliputi struktur organisasi, perencanaan, tanggung jawab, pelaksanaan, penerapan, pencapaian, pengkajian dan pemeliharaaan kebijakan keselamatan dan kesehatan kerja dalam rangka pengendalian risiko yang berkaitan dengan kegiatan kerja guna terciptanya tempat kerja yang aman, efesien dan produktif. Kesehatan kerja merupakan salah satu bidang kesehatan masyarakat yang memfokuskan perhatian pada masyarakat pekerja baik yang berada di sektor formal maupun yang berada di sektor informal.

Kegiatan manajemen risiko merupakan isu penting bagi sebuah pelayanan yang berbasis mutu pelayanan. Manajemen risiko merupakan upaya preventif bagi sebuah perusahaan terutama yang bergerak pada bidang jasa dimana rentan sekali dengan kesalahan dan komplain. Untuk itu perlu adanya pemetaan terlebih dahulu risiko yang terjadi sesuai dengan unit kerja yang ada didalamnya. Dengan itu melakukan manajemen risiko diharapkan dapat meminimalisir angka kejadian kecelakaan atau kesalahan baik pada pasien, pengunjung maupun pegawai yang ada di rumah sakit. Dalam mencapai keberhasilan untuk mewujudkan pengendalian dan mitigasi terhadap risiko di suatu pelayanan kesehatan maka perlu untuk dibuatkan aturan serta tata cara dan target kerja sehingga jelas sesuai dengan agenda yang telah ditetapkan. Untuk itu manajemen risiko membuat kebijakan dan strategi yang akan digunakan 


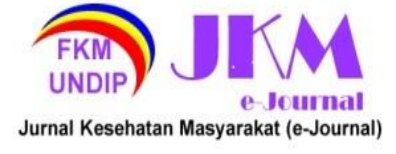

dalam proses tersebut. Hal ini dimaksudkan agar tidak terjadi kesalahan dalam identifikasi sampai dengan monitoring program kerja sehingga bisa fokus untuk melakukan dan merencanakan kegiatan di unit pelayanan.

Rumah Sakit Islam Surabaya A. Yani merupakan Rumah sakit yang berada di bawah naungan Yayasan Rumah Sakit Islam Surabaya (YARSIS). Rumah Sakit Islam Surabaya yang merupakan salah satu rumah sakit swasta dengan

\section{JURNAL KESEHATAN MASYARAKAT (e-Journal) \\ Volume 10, Nomor 1, Januari 2022 \\ ISSN: 2715-5617 / e-ISSN: 2356-3346 \\ http://ejournal3.undip.ac.id/index.php/jkm}

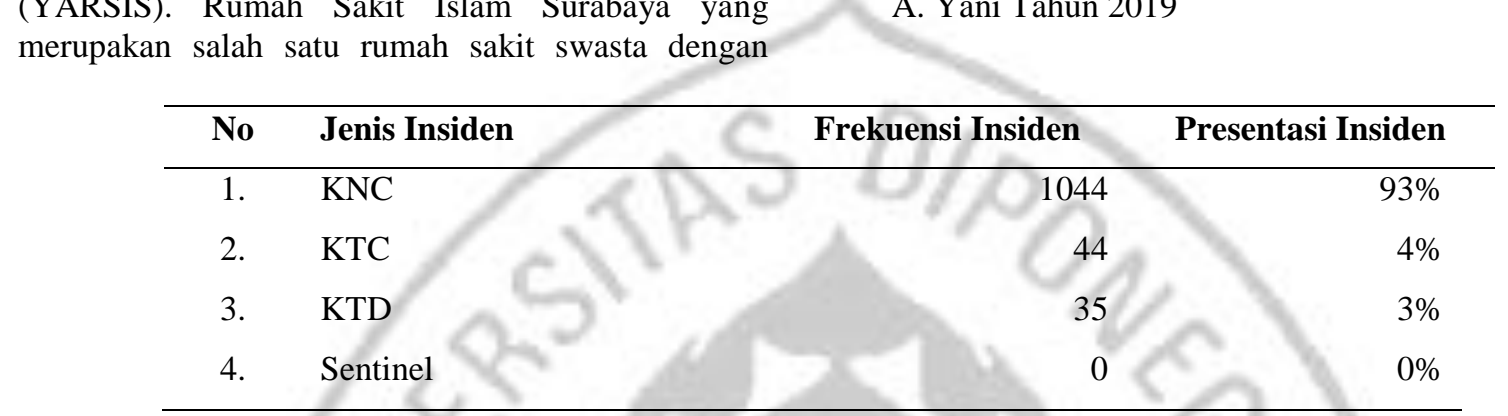

Sumber: Rumah Sakit Islam Surabaya A. Yani 2019

Berdasarkan tabel data laporan kejadian insiden keselamatan pasien tahun 2019 dijelaskan bahwa jumlah presentase frekuensi insiden keselamatan pasien berdasarkan jenis insidennya adalah KNC 93\%, KTC 4\%, KTD 3\% dan Sentinel 0\% di Rumah Sakit Islam Surabaya A. Yani. Dengan itu untuk meningkatkan pelayanan dan kepuasan konsumen, diperlukan adanya peningkatan dalam pelayanan patient safety. Perlu adanya pemantauan secara berkala dan manajemen risiko yang baik untuk memastikan keselamatan kerja terhadap tenaga kesehatan, pasien dan pengunjung yang berada di Rumah Sakit Islam Surabaya A. Yani. berdasarkan pada uraian tersebut, maka penulis mengadakan penelitian mengenai "Penerapan Manajemen Risiko Keselamatan dan Kesehatan Kerja Di Rumah Sakit Islam Surabaya A. Yani”.

Adapun tujuan umum dan khusus dari penelitian ini adalah untuk mengetahui penerapan manajemen risiko K3 di Rumah Sakit Islam Surabaya A. Yani. Mengidentifikasi risiko keselamatan dan kesehatan Kerja di Rumah Sakit Islam Surabaya A. Yani. Menganalisis dan evaluasi risiko di Rumah Sakit Islam Surabaya A. Yani, serta mengetahui pengendalian dari risiko di Rumah Sakit Islam Surabaya A. Yani. Selain itu, penelitian ini diharapkan dapat menjadi bahan referensi dan menambah informasi serta wawasan pengetahuan tentang manajemen risiko keselamatan dan kesehatan kerja di Rumah Sakit Islam Surabaya A. Yani. Penelitian ini dapat beramanfaat bagi pihak instansi sebagai masukan dan membantu dalam penerapan manajemen risiko dalam upaya pengendalian risiko pelayanan yang baik dan terakreditasi Paripurna (Bintang Lima) oleh KARS. Dengan ini pasien dan pengunjung mengharapkan untuk mendapatkan pelayanan yang baik dan memuaskan. Berdasarkan data laporan kejadian insiden kesalamatan pasien tahun 2019 didapati bahwa jumlah kejadian insiden sebagai berikut:

Data laporan insiden di Rumah Sakit Islam Surabaya A. Yani Tahun 2019 


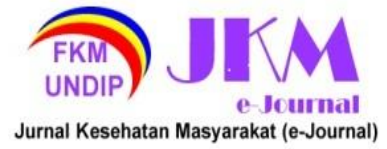

Pada penelitian ini, teknik yang digunakan dalam pengumpulan data terbagi berdasarkan sumber data yang diperoleh, yaitu data primer dan data sekunder. Data primer adalah data yang diperoleh langsung dari obyek penelitian yaitu seluruh unit dan tempat kerja di Rumah Sakit Islam Surabaya A. Yani melalui observasi dan survey menggunakan form identifikasi potensi risiko. Sedangkan data sekunder diperoleh dari rekap data tahunan yang bersifat laporan yang tercatat di Rumah Sakit Islam Surabaya A. Yani. Sedangkan tekhnik analisis data yang digunakan adalah observasi, survey, dan dokumentasi. Observasi yang dilakukan adalah dengan pengamatan langsung terhadap seluruh unit dan tempat kerja di Rumah Sakit Islam Surabaya A. Yani yang berpotensi memiliki risiko dan bahaya serta untuk mendapatkan data sekunder yaitu laporan dari unit PMKP.

Survey ini dilakukan dengan menggunakan form identifikasi risiko untuk mendapatkan informasi dari lapangan mengenai potensi risiko bahaya yang menyebabkan kecelakaan pada tenaga kesehatan, karyawan dan pengunjung atau pasien di Rumah Sakit Islam Surabaya A. Yani. Dokumentasi dilakukan dengan tujuan untuk melengkapi informasi-informasi yang diperoleh agar lebih lengkap serta menunjang kebenaran dan keterangan yang diberikan yang berhubungan dengan identifikasi potensi risiko bahaya. Dari semua tahapan proses tersebut peneliti melakukan input data yang telah diperoleh dalam form identifikasi risiko untuk kemudian di deskripsikan dengan dilengkapi foto atau dokumentasi sesuai dengan keadaan di lapangan dan di deskripsikan dalam bentuk narasi dalam pembahasan dan hasil penelitian.

Setelah mendapatkan semua data yang diperoleh dari penelitian kemudian dianalisis untuk menentukan potensi bahaya atau penyebab kecelakaan beserta sumbernya, dan ditinjau upaya pengendalian yang telah dilakukan sesuai dengan standart AS/NZS 4360 khususnya dengan melakukan analisis risiko bahaya untuk mengetahui tingkat prioritas risiko sebagai langkah pengendalian risiko agar tidak menyebabkan kecelakaan kerja.

\section{PEMBAHASAN}

Pada kegiatan penelitian yang telah dilaksanakan di Rumah Sakit Islam Surabaya A. Yani peneliti mengamati dan fokus pada salah satu kegiatan yaitu penerapan manajemen risiko K3 yang meliputi identifikasi risiko, analisis risiko dan upaya dalam pengendalian risiko. Implementasi dalam program manajemen risiko di Rumah Sakit Islam Surabaya A. Yani sedikit terhambat yang disebabkan oleh pandemi Covid-19 yang menyebabkan pemantauan atau pemeriksaan tidak sesuai dengan jadwal yang sudah ditentutakan. Panitia K3 RSI A. Yani mendukung dan mendorong penerapan manajemen risiko dengan beberapa tahap yaitu: Pertama, Berkomunikasi dan menunjukkan dukungan untuk manajemen risiko. Kedua, Mempercayai, melaporkan setiap kejadian atau insiden dan mengelola risiko. Ketiga, Menghargai dan memberdayakan praktik manajemen risiko yang baik. Keempat, Mengidentifikasi dan pengelolaan berkelanjutan tentang faktor penyebab kecelakaan atau insiden yang terjadi di Rumah Sakit Islam Surabaya A. Yani. Kelima, Mendorong pembelajaran organisasi dengan strukrur dan tugas yang sudah dibentuk. Keenam, Mengembangkan strategi penanganan risiko yang tepat untuk mengurangi kemungkinan atau terulangnya masalah insiden, dan Ketujuh, Pemantauan berkelanjutan dan evaluasi terhadap strategi yang diterapkan untuk memastikan sudah efektif atau tidak.

Pelaksanaan manajemen risiko $\mathrm{K} 3$ merupakan bagian keseluruhan yang meliputi struktur organisasi, perencanaan, tanggung jawab, pelaksanaan, prosedur, proses dan sumber daya yang dibutuhkan bagi pengembangan, penerapan, pencapaian, pengkajian dan pemeliharaan kebijakan $\mathrm{K} 3$ dalam rangka pengendalian risiko atau pencegahan terhadap terjadinya kecelakaan akibat kerja dan penyakit akibat kerja agar tercipta tempat kerja yang aman, nyaman dan produktif.

Menurut Pedoman Manajemen Keselamatan dan Kesehatan Kerja (K3) di Rumah Sakit, manajemen K3RS adalah suatu proses kegiatan yang dimulai dengan tahap perencanaan, pengorganisasian, pelaksanaan dan pengendalian yang bertujuan untuk membudayakan K3 di Rumah Sakit. ${ }^{2}$ Adapun analisis dalam pelaksanaan penelitian ini mengacu pada 4 elemen pokok yang dimuat dalam Kepmenkes (2007) yaitu Komitmen dan Kebijakan, Perencanaan, Pengorganisasian dan Penyelenggaraan. ${ }^{2}$

Berdasarkan hasil penelitian dapat disimpulkan bahwa komitmen Rumah Sakit Islam Surabaya A. Yani yang berkaitan dengan K3RS adalah komitmen awal yang diungkapkan secara lisan, akan tetapi belum diwujudkan dalam bentuk tertulis yang secara khusus tentang K3. Akan tetapi kebijakan mengenai struktur dan organisasi sudah terbentuk dan beberapa program kerja sudah berjalan meski sedikit terhambat di tahun 2020 yang disebabkan oleh pandemi Covid19. Selain itu pendanaan terkait K3RS dan fasilitas seperti alat pelindung diri (APD) sudah lengkap dan diterapkan. 


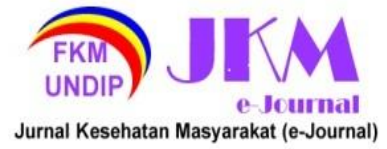

Sumber daya manusia yang menangani K3RS pada Rumah Sakit Islam Surabaya A. Yani terdapat beberapa belum memiliki keahlian khusus di bidang K3, dikarenakan sistem pelatihan dilaksanakan secara bergilir dan bergantian, sumber daya yang sudah ada perlu di ikutkan dalam pelatihan K3 sehingga rumah sakit memiliki sumber daya yang berkompeten yang diwujudkan dalam bentuk wadah organisasi panitia K3RS. Rumah Sakit Islam Surabaya A. Yani juga mempunyai kebijakan bahwa semua pekerja di rumah sakit aharus mendapatkan penyuluhan mengenai $\mathrm{K} 3$.

Diketahui bahwa beberapa strategi yang sudah tersusun di Rumah Sakit Islam Surabaya A. Yani yaitu sosialisasi program K3RS, terbentuknya organisasi panitia K3 meskipun belum menjadi organisasi yang mandiri dan masih berada dalam bidang pelayananan serta beberapa SDM di panitia $\mathrm{K} 3$ yang belum mempunyai basic dari K3 akan tetapi mereka mendapatkan pelatihan yang memadai serta program kerja yang sudah tersusun.

Analisis Risiko merupakan proses untuk mengidentifikasi serta memberikan penilaian risiko yang mengukur dampak, frekuensi atau probabilitas serta besarnya kerugian kepada penerima yang disebabkan oleh paparan bahaya yang mengakibatkan kecelakaan kerja atau penyakit akibat kerja. Berdasarkan penilaian risiko dengan hasil kali dari dampak, tingkat probabilitas dan kerugian kepada penerima di Rumah Sakit Islam Surabaya A. Yani melalui proses survey dan observasi dengan menggunakan form identifikasi risiko dari Panitia K3 Rumah Sakit Islam Surabaya A. Yani dengan standard AS/NZS 4360 didapatkan beberapa risko sedang dan risiko tinggi di gedung graha serta gedung lama yang berjumlah 37 unit atau bagian yang beresiko dapat menyebabkan kecelakaan kerja pada tenaga kesehatan, karyawan, pasien dan pengunjung.

Risiko sedang yang ditemukan seperti penempatan barang yang berelebihan di ruang kerja yang mempersempit luas ruang kerja, penempatan alat kesehatan disepanjang jalan dan disekitar tangga, kebocoran air dari atap yang membasahi lantai yang beresiko terpeleset, karet lantai yang sudah mengelupas dan terdapat gundukan di permukaan lantai yang dapat mengakibatkan tenaga kesehatan serta pengunjung dan pasien terjatuh atau tersandung ketika tidak sengaja melewati titik lokasi, risiko lainnya seperti kabel instalasi komputer atau dispenser di ruang kerja berantakan dan berdekatan dengan aktivitas pekerjaan yang berisiko dapat mengakibatkan gangguan arus listrik, tersengat listrik dan dapat terjadinya fong, kemudian tandon atau pompa air yang tidak terkunci yang berisiko masuknya hewan serangga atau vector yang dapat mengakibatkan air berbau atau tercemar dan penempatan barang berlebih di ruang kerja yang berisiko pada tenaga kerja saat melakukan aktivitas pekerjaan terjatuh atau tersandung barang.

Risiko tinggi diantaranya seperti sistem instalasi listrik dan tendon air yang tidak terkunci yang dapat mengakibatkan dibobol oleh orang yang jail dan tidak bertanggung jawab dan mengakibatkan sistem kelistrikan rumah sakit terngganggu dan bermasalah, peletakkan APAR yang posisinya terlalu tinggi serta dekat dengan aktivitas kerja yang berisiko jatuh dan menimpa orang yang berada dekat di tiitk lokasi tersebut, kemudian pengecekan APAR yang tidak terjadwal sehingga kondisi APAR kurang baik seperti karet atau selang yang sudah mengelupas dan expired sehingga penggunaan APAR saat dibutuhkan dan terjadi kebakaran dapat terhambat. Risiko lainnya adalah atap ruang pertemuan di gedung lama mengelupas dan hampir roboh yang berisiko jatuh tertimpa orang yang berada di ruangan tersebut dan menimbulkan dampak yang merugikan dan kabel yang berserakan dan berantakan yang berada didekat aktivitas kerja serta perangkat komputer, hal tersebut dapat beresiko terjadi gangguan arus listrik dan fong serta dapat memicu terjadinya kebakaran.

Langkah pengendalian yang dapat dilakukan dari risiko yang ditemukan adalah seperti kondisi dinding-dinding runnah sakit dibeberapa titik yang sudah retak dan atap yang mengalami kebocoran serta lantai yang retak dan berlubang dan beberapa karet lantai yang mulai mengelupas serta penempatan barang yang berserakan di sekitar jalan dan ruang kerja, kabel yang berserakan, permukaan lantai yang basah dan licin di beberapa titik lokasi yang diantaranya dapat mengakibatkan kecelakaan kerja bagi tenaga kesehatan, karyawan dan pasien atau pengunjung di Rumah Sakit Islam Surabaya A. Yani. Beberapa pengendalian risiko yang dapat dilakukan di gedung graha adalah sebagai berikut:

Tabel 1. Pengendalian Risiko Gedung Graha RSI Surabaya A. Yani 


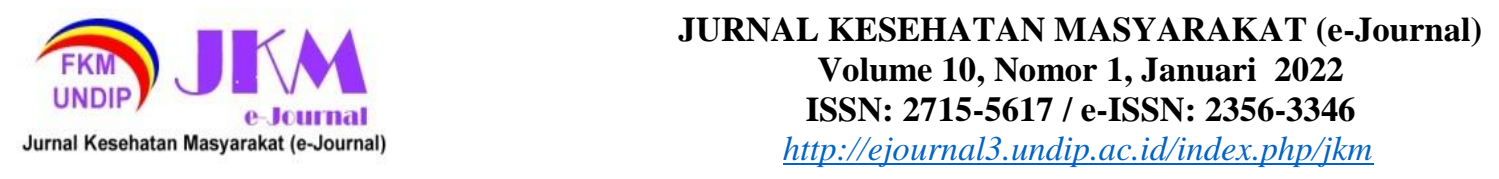

\begin{tabular}{|c|c|c|c|}
\hline No & Risiko yang mungkin terjadi & Akar Masalah & Rekomendasi Pengendalian \\
\hline 1 & $\begin{array}{l}\text { - Tersandung } \\
\text { - Tertimpa benda } \\
\text { - Terjatuh }\end{array}$ & $\begin{array}{l}\text { Penempatan barang yang } \\
\text { berlebihan di ruang kerja }\end{array}$ & $\begin{array}{l}\text { Ditempatkan ditempat yang lebih aman } \\
\text { seperti gudang atau ruang penyimpanan } \\
\text { lainnya. }\end{array}$ \\
\hline 2 & $\begin{array}{l}\text { - Tertabrak alkes } \\
\text { - APAR terhalang } \\
\text { - Tersandung alkes }\end{array}$ & $\begin{array}{l}\text { Penempatan } \\
\text { disekitar APAR }\end{array}$ & $\begin{array}{l}\text { Ditempatkan ditempat yang lebih aman } \\
\text { seperti gudang atau ruang penyimpanan } \\
\text { lainnya. }\end{array}$ \\
\hline 3 & $\begin{array}{l}\text { - Terpeleset } \\
\text { - Terjatuh }\end{array}$ & $\begin{array}{l}\text { Kebocoran air dari atap } \\
\text { yang membasahi lantai }\end{array}$ & $\begin{array}{l}\text { Perbaikan atap dan atau pemberian tanda } \\
\text { lantai licin disekitar lantai tersebut. }\end{array}$ \\
\hline 4 & $\begin{array}{l}\text { - APAR tidak dapat di } \\
\text { maksimal saat terjadi keb }\end{array}$ & $\begin{array}{l}\text { Selang APAR yang lepas } \\
\text { dan tidak terawat }\end{array}$ & $\begin{array}{l}\text { Perbaikan dan pengecekan APAR secara } \\
\text { rutin atau terjadwal }\end{array}$ \\
\hline 5 & - Tertimpa APAR & $\begin{array}{l}\text { Peletakkan APAR yang } \\
\text { terlalu tinggi }\end{array}$ & $\begin{array}{l}\text { Peletakkan APAR di posisi yang } \\
\text { ketinggian yang benar dan strategis }\end{array}$ \\
\hline 6 & $\begin{array}{l}\text { - Tersandung } \\
\text { - Tertabrak } \\
\text { - Terjatuh }\end{array}$ & $\begin{array}{l}\text { Kursi roda di lorong } \\
\text { jalan }\end{array}$ & $\begin{array}{l}\text { Memindahkan ditempat yang lebih aman } \\
\text { dan tidak menghalangi aktivitas kegiatan } \\
\text { di lingkungan kerja }\end{array}$ \\
\hline 7 & $\begin{array}{l}\text { - Kebisingan } \\
\text { - Gangguan pendengaran }\end{array}$ & $\begin{array}{l}\text { Mesin menimbulkan } \\
\text { suara bising }\end{array}$ & $\begin{array}{l}\text { Menyimpannya di ruangan yang dapat } \\
\text { meredam suara dan memakai ear plug }\end{array}$ \\
\hline 8 & $\begin{array}{l}\text { - Terpeleset } \\
\text { - Terjatuh }\end{array}$ & $\begin{array}{l}\text { Atap yang retak dan } \\
\text { bocor }\end{array}$ & Menambal dan memperbaiki atap \\
\hline 9 & $\begin{array}{l}\text { - Gangguan arus listrik } \\
\text { - Tersengat arus listrik } \\
\text { - Dapat terjadi fong }\end{array}$ & $\begin{array}{l}\text { Kabel yang berantakan } \\
\text { dan berdekatan dengan } \\
\text { aktivitas kerja }\end{array}$ & $\begin{array}{l}\text { Merapikan kabel dan memberikan } \\
\text { pengunci pengaman kabel }\end{array}$ \\
\hline 10 & $\begin{array}{l}\text { - Tertimpa benda } \\
\text { - Rusaknya Fasilitas } \\
\text { - Gangguan arus listrik }\end{array}$ & $\begin{array}{l}\text { Meletakan benda atau } \\
\text { barang di atas galon yang } \\
\text { berdekatan } \\
\text { komputer }\end{array}$ & $\begin{array}{l}\text { Memindahkan benda ke tempat yang } \\
\text { sudah disediakan seperti laci atau meja }\end{array}$ \\
\hline
\end{tabular}

Berdasarkan table pengendalian risiko di gedung graha di Rumah Sakit Islam Surabaya A. Yani, hasil identifikasi risiko serta analisis risiko didapatkan langkah pengendalian yang dapat dilakukan di gedung graha adalah meliputi menyedikan tempat atau fasilitas penyimpanan barang dan alat kesehatan agar tidak ditempatkan di sekitar ruang kerja yang akibatnya dapat mempersempit luas ruang kerja, memperbaiki fasilitas sarana prasarana yang sudah rusak seperti atap yang retak dan dinding yang bocor saat hujan agar terhindar dari risiko terpeleset yang diakibatkan oleh lantai yang basah, merapikan kabel dan memberikan pengaman tambahana agara kabel tidak berantakan dan terjadi gangguan arus listrik, memeperbaiki sistem keamanan serta pengecekan fasilitas secara terjadwal dan berkala seperti APAR agar selalu terjaga dan terawatt serta terhindar dari pembobolan oleh orang yang jail dan tidak bertanggung jawab. Risiko kebisingan yang disebabkan oleh mesin di ruang hemodialisis lantai 1 telah berhasil dikendalikan dengan menyediakan dan memindahkan mesin kedalam ruang kedap suara agar tidak menimbulkan kebisingan yang berlebih dan mengganggu pendengaran orang di rumah sakit.

Pengendalian risiko juga dilakukan di gedung lama Rumah Sakit Islam Surabaya A. Yani sesuai dengan hasil identifikasi dan analisis risiko. Adapun 


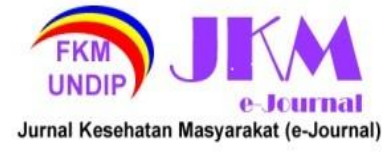

pengendalian yang dapat dilakukan adalah sebagai berikut:

\section{JURNAL KESEHATAN MASYARAKAT (e-Journal) \\ Volume 10, Nomor 1, Januari 2022 \\ ISSN: 2715-5617 / e-ISSN: 2356-3346 \\ http://ejournal3.undip.ac.id/index.php/jkm}

\begin{tabular}{|c|c|c|c|}
\hline No & Risiko yang mungkin terjadi & Akar Masalah & Rekomendasi Pengendalian \\
\hline 1 & $\begin{array}{l}\text { - Tersandung } \\
\text { - Terpeleset } \\
\text { - Terjatuh }\end{array}$ & $\begin{array}{l}\text { Tangga yang kurang lebar } \\
\text { dan tidak terdapat } \\
\text { pengaman seperti karet di } \\
\text { pijakan tangga }\end{array}$ & 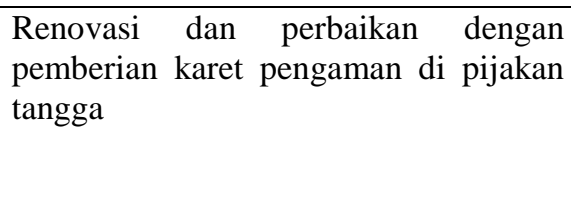 \\
\hline 2 & $\begin{array}{l}\text { - Sistem keamanan ter } \\
\text { - Gangguan listrik } \\
\text { - Kegagalan jaringan }\end{array}$ & $\begin{array}{l}\text { Ruang instalasi listri } \\
\text { tidak terkunci }\end{array}$ & $\begin{array}{l}\text { dan mengunci ruangan } \\
\text { digunakan }\end{array}$ \\
\hline 3 & $\begin{array}{l}\text { - Tertabrak ba } \\
\text { - Terjatuh } \\
\text { - Tersandung }\end{array}$ & $\begin{array}{l}\text { Meletakan barang } \mathrm{d} \\
\text { alkes di tangga }\end{array}$ & $\begin{array}{l}\text { Memindahkan barang ditempat yang } \\
\text { aman }\end{array}$ \\
\hline 4 & $\begin{array}{l}\text { - Tersandung } \\
\text { - Terjatuh } \\
\text { - Terjungkal }\end{array}$ & $\begin{array}{l}\text { Lantai retak dan berlu } \\
\text { di koridor farmasi }\end{array}$ & in perbaikan pada lantai \\
\hline 5 & $\begin{array}{l}\text { - Kemasukan serangga ata } \\
\text { - Air berbau }\end{array}$ & $\begin{array}{l}\text { Tandon air untuk oksigen } \\
\text { tidak terkunci dan kurang } \\
\text { terawat }\end{array}$ & $\begin{array}{l}\text { Pengecekan dan pemantauan secara } \\
\text { berkala serta di gembok }\end{array}$ \\
\hline 6 & $\begin{array}{l}\text { - Tlusupan kayu } \\
\text { - Tergores kaca yang reta }\end{array}$ & $\begin{array}{l}\text { Fasilitas sanitasi ruang } \\
\text { klinik dan rohani yang } \\
\text { sudah terkelupas dan kaca }\end{array}$ & Perbaikan fasilitas sanitasi \\
\hline 7 & $\begin{array}{l}\text { - Tertimpa kaca } \\
\text { - Tersandung }\end{array}$ & $\begin{array}{l}\text { Penempatan kaca yang } \\
\text { berada di jalan }\end{array}$ & $\begin{array}{l}\text { Memindahkan di tempat yang lebih } \\
\text { aman }\end{array}$ \\
\hline 8 & $\begin{array}{l}\text { - Tersandung } \\
\text { - Terjatuh } \\
\text { - Terjungkal }\end{array}$ & $\begin{array}{l}\text { Penempatan pipa di } \\
\text { sepanjang jalan yang } \\
\text { sering terdapat aktivitas }\end{array}$ & $\begin{array}{l}\text { Memindahkan pipa di lokasi yang lebih } \\
\text { aman atau digudang }\end{array}$ \\
\hline 9 & $\begin{array}{l}\text { - Gangguan arus listrik } \\
\text { - Tersengat arus listrik } \\
\text { - Dapat terjadi fong }\end{array}$ & $\begin{array}{l}\text { Kabel yang berantakan dan } \\
\text { berdekatan rengan } \\
\text { aktivitas kerja }\end{array}$ & $\begin{array}{l}\text { Merapikan kabel dan memberikan } \\
\text { pengunci pengaman kabel }\end{array}$ \\
\hline 10 & $\begin{array}{l}\text { - Terjatuh } \\
\text { - Tersandung } \\
\text { - Tertabrak }\end{array}$ & $\begin{array}{l}\begin{array}{l}\text { Penempatan } \\
\text { ruang kerja }\end{array} \\
\end{array}$ & $\begin{array}{l}\text { Menyimpannya di gudang atau di } \\
\text { tempat yang lebih aman }\end{array}$ \\
\hline 11 & $\begin{array}{l}\text { - Terpeleset } \\
\text { - Tersandung } \\
\text { - Terjatuh }\end{array}$ & $\begin{array}{l}\text { Karet lantai yang mulai } \\
\text { mengelupas }\end{array}$ & Memperbaiki dan mengganti karet \\
\hline 12 & $\begin{array}{l}\text { - Terpeleset } \\
\text { - Terjatuh }\end{array}$ & $\begin{array}{l}\text { Kebocoran air dari atap } \\
\text { yang membasahi lantai }\end{array}$ & $\begin{array}{l}\text { Perbaikan atap dan atau pemberian } \\
\text { tanda lantai licin disekitar lantai } \\
\text { tersebut. }\end{array}$ \\
\hline
\end{tabular}

Tabel 2. Pengendalian Risiko Gedung Lama RSI Surabaya A. Yani 


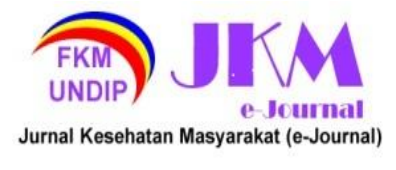

\section{JURNAL KESEHATAN MASYARAKAT (e-Journal) \\ Volume 10, Nomor 1, Januari 2022 \\ ISSN: 2715-5617 / e-ISSN: 2356-3346 \\ http://ejournal3.undip.ac.id/index.php/jkm}

\begin{tabular}{llll}
\hline 13 & $\begin{array}{l}\text { - Pembobolan orang yang usil } \\
\text { - Sistem kelistrikan mati saat } \\
\text { dibutuhkan }\end{array}$ & $\begin{array}{l}\text { Instalasi listrik yang tidak } \\
\text { terkunci }\end{array}$ & $\begin{array}{l}\text { Penguncian dan pengecekan secara } \\
\text { berkala }\end{array}$ \\
\hline 14 & - Terjatuh & Akses jalan dan lorong \\
& - Terpeleset & $\begin{array}{l}\text { yang curam di lorong ICU } \\
\text { dan tidak ada pengaman } \\
\text { atau pijakan }\end{array}$ & $\begin{array}{l}\text { Menambahkan pegangan di masing- } \\
\text { masing sisi serta pijakan seperti anak } \\
\text { tangga }\end{array}$ \\
& Tidak Ergonomi & $\begin{array}{l}\text { Jalan yang terbuka di } \\
\text { sekitar genset dan tidak } \\
\text { terkunci }\end{array}$ & $\begin{array}{l}\text { Menutup pagar dan menguncinya sert } \\
\text { atidak digunakan menjadi akses jalan }\end{array}$ \\
\hline 15 & - Tersengat aliran listrik & Rawan Konsleting saat hujan & \\
& &
\end{tabular}

Berdasarkan table pengendalian risiko di gedung lama Rumah Sakit Islam Surabaya A. Yani didapatkan beberapa pengendalian lainnya juga yang dapat dilakukan seperti menjaga dan mengunci sistem kelistrikan serta tandon dan sumber air agar tidak dibobol orang lain yang jail dan tidak bertanggung jawab serta agar terhindar dari kemasukan vector yang dapat mengakibatkan air rumah sakit berbau dan tercemar. Pengendalian risiko juga dapat dilakukan dengan menyediakan tempat atau ruang penyimpanan agar tidak menempatkan barang disekitar ruang kerja yang berdampak pada sempitnya ruang kerja sehingga risiko terjatuh dan tersandung barang sering terjadi, menyediakan kursi dan meja yang ergonomis sehingga tidak menimbulkan penyakit akibat kerja pada karyawan dan meningkatkan kinerja, pencahayaan yang baik di setiap unit atau ruang kerja agar tenaga kerja tidak mudah lelah akibat pencahayaan yang kurang dan tidak mengganggu aktivitas kerja di rumah sakit.

Mengatur suhu ruang kerja dan memberikan ventilasi pada setiap ruangan untuk mengalirkan udara dari luar ke dalam ruangan dan sebaliknya agar siklus pergantian udara dalam ruangan menjadi teratur dan sehat serta menjadi saluran dari keluarnya polusi dari ruang kerja, enempatkan barang seperti kaca ke tempat yang aman dan tidak beresiko terjangkau atau tertabrak oleh tenaga kesehatan, pengunjung atau pasien, memperbaiki karet lantai yang sudah mengelupas dan lantai yang retak agar terhindar dari risiko terjatuh ataupun tersandung, memperbaiki kebocoran dan memberikan tanda lantai basah apabila di titik tersebut terdapat genangan air yang disebabkan oleh kebocoran.

\section{KESIMPULAN}

Berdasarkan penelitian penerapan manajemen risiko keselamatan dan kesehatan kerja di Rumah Sakit Islam Surabaya A. Yani didapatkan kesimpulan, bahwa implementasi manajemen risiko K3 dalam program manajemen risiko di Rumah Sakit Islam Surabaya A. Yani berjalan baik namun belum optimal karena disebabkan oleh pandemi Covid-19 yang menyebabkan pemantauan atau pemeriksaan tidak sesuai dengan jadwal yang sudah ditentukan. Identifikasi risiko didapatkan 25 potensi risiko yang terdapat di 37 unit yang meliputi gedung graha dan gedung lama di Rumah Sakit Islam Surabaya A. Yani, adapun risiko yang ada meliputi risiko terjatuh, tersandung, terpeleset, tersengat arus litrik, terbobolnya sistem keamanan dan risiko kebisingan. Analisis risiko di Rumah Sakit Islam Surabaya terdapat 25 potensi risiko di gedung graha dan gedung lama, diantaranya terdapat 15 risiko sedang dan 10 risiko tinggi. Gedung graha terdapat 7 risiko sedang dan 3 risiko tinggi sedangkan gedung lama terdapat 8 risiko sedang dan7 risko tinggi. Pengendalian risiko yang dapat dilakukan adalah dengan memperbaiki sarana prasarana yang sudah mulai rusak, menyediakan tempat atau ruang khusus untuk menyimpan barang dan alat kesehatan serta memperbaiki sistem keamanan untuk menghindari terbobolnya instalasi listrik dan tendon air oleh orang yang tidak bertanggung jawab dan melakukan pengecekan serta pemantauan secara terjadwal.

\section{DAFTAR PUSTAKA}

1. Cresswell, J. W. Qualitative Inquiry \& Research Design; 2007.

2. Menkes RI. Peraturan Menteri Kesehatan No.11 2007 tentang Keselamatan Pasien; 2007.

3. Alfajri, I. K3 Merupakan Tanggung Jawab Perusahaaan; 2012.

4. AS/NZS 4360. . Risk Management. Australian/New Zealand Standard 4360; 2004.

5. Bennet, S. Manajemen Keselamatan dan Kesehatan Kerja. Jakarta; 1995.

6. CMRS Indonesia. Survei Nasional Manajemen Risiko; 2018.

7. ISO 31000., 2018. ISO 31000: 2018 Risk Management - Guidelines. Switzerland: ISO Organization. 

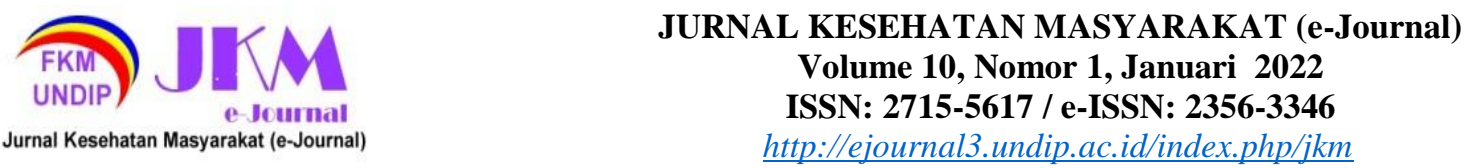

8. KKPRS. Pedoman Pelaporan Insiden Keselamatan Pasien (IKP). Kementrian Kesehatan republik Indonesia; 2015.

9. Menkes RI. Peraturan Menteri Kesehatan Republik Indonesia Nomor 71 Tahun 2013 tentang Pelayanan Kesehatan Pada Jaminan Kesehatan Nasional; 2013.

10. Menkes RI. Peraturan Menteri Kesehatan Republik Indonesia Nomor 44 Tahun 2018 tentang Penyelenggaraan Promosi Kesehatan Rumah Sakit; 2018.

11. Murdiyono. Identifikasi Bahaya, Penilaian dan Pengendalian Risiko di Bengkel Pengelasan SMKN 2 Pengasih. Skripsi. Yogyakarta: Universitas Negeri Yogyakarta; 2016.

12. NHS. NHS Bradford City Clinical Commissioning Group \& NHS Bradford Districts CLinical Commissioning Group; Risk Management Strategy \& Risk Register Policy; 2015.

13. NHS. Policy and Guidance for the Use of Risk Register; 2008.

14. Notoadmodjo, S. Kesehatan Masyarakat Ilmu dan Seni; 2007.

15. Nurgraheni, M, Baju, W., Bina, K. \& Ekawati. Faktor-Faktor yang Berhubungan dengan Pencegahan Jatuh pada Pasien risiko Jatuh oleh Perawat di Ruang Nusa Indah RSUD Tugurejo Semarang. Junal Kesehatan Masyarakat 2017; (eJournal),. Volume 5, (ISSN: 2356-3346).

16. PERMENKES RI. Peraturan Menteri Kesehatan Republik Indonesia Nomor 11 tahun 2017 tentang Keselamatan Pasien; 2017.

17. Republik Indonesia. Undang-Undang RI Nomor 44 Tahun 2009 Tentang Rumah Sakit; 2009.

18. Sanjaya, P. D., Elsye, M.R. \& Maria U. Evaluasi Penerapan Pencegahan Pasien Berisiko Jatuh di Rumah Sakit. Jurnal Fakultas Kesehatan Masyarakat, 2017; Volume 11(Issue 2), pp. pp 105-113.

19. Soehatman, R. Pedoman Praktis Manajemen Bencana; 2010.

20. Sahab, S. Maanajemen Keselamatan Kerja. Jakarta; 1997.

21. Tarwaka. Keselamatan dan Kesehatan Kerja Manajemen Implementasi K3 di Tempat Kerja. Surakarta: Harapan Press; 2008.

22. Wilkinaom. J. M. Buku Saku Diagnosis Keperawatan: Diagnosis NANDA, Intervensi NIC, Kriteria Hasil NOC. Edisi 9. Jakarta: 2011. 